\title{
Методы оценки сорбционной емкости кормовых добавок in vitro (обзор)
}

Гогина Н.H., кандидат сельскохозяйственных наук, старший научный сотрудник отдела физиологии и биохимии ФГБНу Федеральный научный центр «Всероссийский научно-исследовательский и технологический институт птицеводства» Российской академии наук (ФНЦ «ВНИТИП» РАН)

\begin{abstract}
Аннотация: Микотоксикозы сельскохозяйственных жиботных наносят значительный экономический ущерб и могут служить причиной снижения качества получаемой продукиии. В настоящее время наиболее эфректибным средством борьбы с этой проблемой ябляется применение кормовых добабок, способных либо сорбировать, либо инактибировать микотоксины 6 процессе пищебарения. Химическое разнообразие и специфика молекулярного строения микотоксинов создает препятствие для одинаково бысокой эфрфективности кормовых добабок по отношению к иирокому спектру данных ксенобиотиков. Поэтому при бнесении 6 рацион той или иной кормобой добабки необходимо учитьвать содержание микотоксинов б корме и способность выбранной кормовой добабки сорбировать (инактибировать) их, а также использовать рациональную дозировку препарата, зависящую от уровня контаминации корма. Для оценки способности кормобой добабки к сорбиии (инактивации) тех или иных микотоксинов бозможно проводить эксперименты in vitro и in vivo. В обзоре рассматриваются применяемые методики in vitro для определения сорбционной способности кормобых добабок по отношению к микотоксинам.
\end{abstract}

ключебые слова: кормовые добабки, микотоксины, сорбция (инактивация) микотоксинов.

Решение актуальной проблемы микотоксикозов сельскохозяйственных животных и птицы при помощи кормовых добавок (КД) в настоящее время считается одним из самых эффективных способов. На рынке Российской Федерации присутствует более 70 различных КД с заявленными свойствами к сорбции микотоксинов [1]. Наиболее известный подход к детоксикации микотоксинов включает использование питательно инертных адсорбентов, а также комплексных КД, содержащих органические компоненты. Особенностью энтеросорбентов является отсутствие собственной фармакокинетики, поскольку они, как правило, нерастворимы и не всасываются в желудочно-кишечном тракте (ЖКТ) [2,3]. Однако не все составляющие кормовых добавок одинаково хорошо сорби- руют все микотоксины. Высокое химическое разнообразие микотоксинов, их малая молекулярная масса и слабая способность $\mathrm{K}$ взаимодействию с другими веществами (низкая полярность) создают препятствие для создания препарата, одинаково эффективного ко всем видам токсинов. Изучение сорбционных свойств КД in vitro является важным подходом к оценке эффективности адсорбентов и созданию новых добавок для сорбции (инактивации) микотоксинов в ЖКТ.

Развитие научных знаний о химической структуре и механизме влияния микотоксинов на организм способствовало эволюции препаратов для борьбы с микотоксикозами. Низкая адсорбционная способность минеральных препаратов первого поколения по отношению к трихотеценовым микотоксинам ста- ла поводом для поиска адсорбционных материалов среди органических веществ. Кормовые сорбенты второго поколения содержат в своем составе органическую часть (компоненты стенок клеток дрожжей). Действие препаратов первого и второго поколений основано только на связывании микотоксинов. Адсорбенты третьего поколения включают известные адсорбенты предыдущего поколения и ферментные препараты. Механизм действия адсорбентов третьего поколения комплексный, так как он основан на адсорбции микотоксинов и ограничении их всасывания, а также на инактивации не адсорбированных токсинов. Препараты четвертого поколения представляют собой комплекс из препаратов первого, второго и третьего поколений и содержат в своем составе комплексы, осу- 
ществляющие деструкцию микотоксинов $[3,4]$.

Лабораторный метод изучения способности КД к взаимодействию с микотоксинами в ЖКТ является способом скрининга эффективных препаратов для конкретной ситуации. Если препарат не адсорбирует микотоксин in vitro, у него практически нет шансов сделать это in vivo $[3,5,6]$. Однако не существует единой общепринятой аттестованной методики для определения эффективности КД в отношении сорбции (инактивации) микотоксинов. В тоже время, методики, применяемые российскими и зарубежными учеными, во многом схожи. В пробирке моделируются условия желудка (кислая среда) для изучения адсорбции микотоксинов и условия кишечника (щелочная среда) для определения десорбции адсорбатов. Под «адсорбцией» подразумевается общее количество микотоксинов, связанных сорбентом за время нахождения корма в кислой среде желудка, под «десорбцией» - удаление с поверхности адсорбента микотоксинов в щелочной среде кишечника. Истинная сорбционная емкость вычисляется как разница между адсорбцией и десорбцией $[7,8,10]$. Инкубацию рабочих растворов в пробирке проводят обычно при температуре $37^{\circ} \mathrm{C}$ и при перемешивании с использованием специальных шейкеровинкубаторов.

В публикациях описаны некоторые моменты проведения эксперимента, которые отличаются в разных лабораториях:

1. Количественный метод, используемый для измерения концентрации микотоксинов в рабочих растворах: непрямой кон-

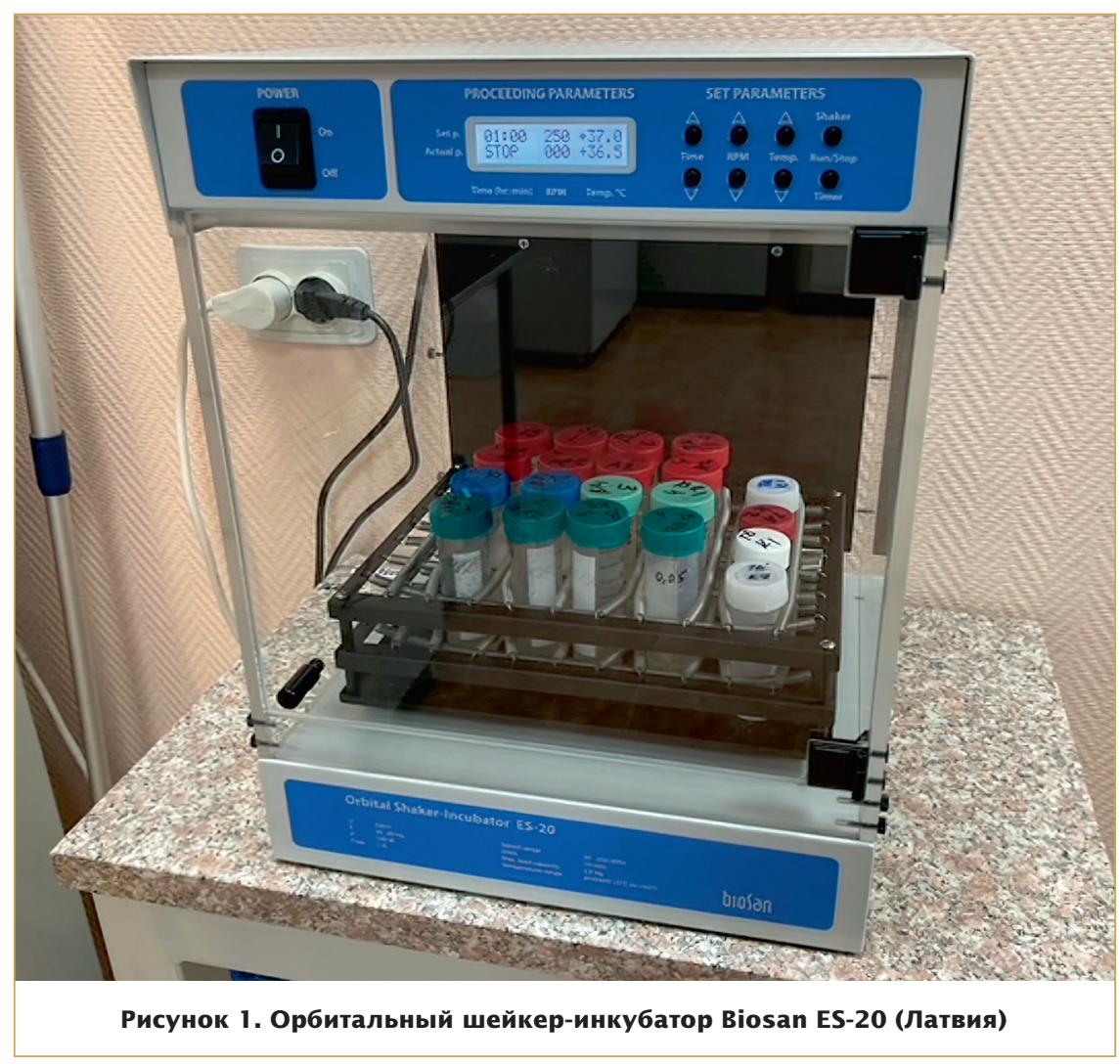

курентный иммуносерментный анализ (ИФА) с применением коммерческих наборов реагентов [7], метод жидкостной хроматографии в тандеме с масс-спектрометрией (ВЖX-MC) MC) [8], метод тонкослойной хроматографии (TCX) с биоавтографическим завершением с использованием культуры Candida pseudotropicalis штамм 44 ПК [9].

2. Кислотность $(\mathrm{pH})$ и состав рабочих растворов. Кислые условия среды создаются добавлением в водный раствор микотоксинов либо уксусной кислоты [7], либо соляной кислоты $(\mathrm{HCl})[2,8,9,10]$. $\mathrm{Ho} \mathrm{pH}$ получаемых растворов варьирует при этом от 1,2 до 3,5 ед. То же касается и рабочего раствора со щелочной средой, где $\mathrm{pH}$ в разных публикациях заявляется от 6,0 до 9,0 ед. Причем щелочная среда в не- которых экспериментах создается путем подщелачивания первоначального раствора [7], а в других - внесением буферного раствора с соответствующим щелочным рН к сорбенту после декантации кислой среды [8-10].

3. Время инкубации рабочих растворов при имитации пищеварения в желудке в разных экспериментах - от 1 до 3 ч. Эксперимент по десорбции микотоксинов в щелочных условиях кишечника проводится в течение 3 ч. Причем в исследовании [2] проводится построение кинетической кривой, когда ряд одинаковых навесок сорбента перемешивают с раствором адсорбата, и в течение фиксированных промежутков времени (5, 15, 30, 60 мин и 2, 4, 6, 12 и 24 и 48 ч) проводят измерение остаточной концентрации адсорбата. Инкубацию 


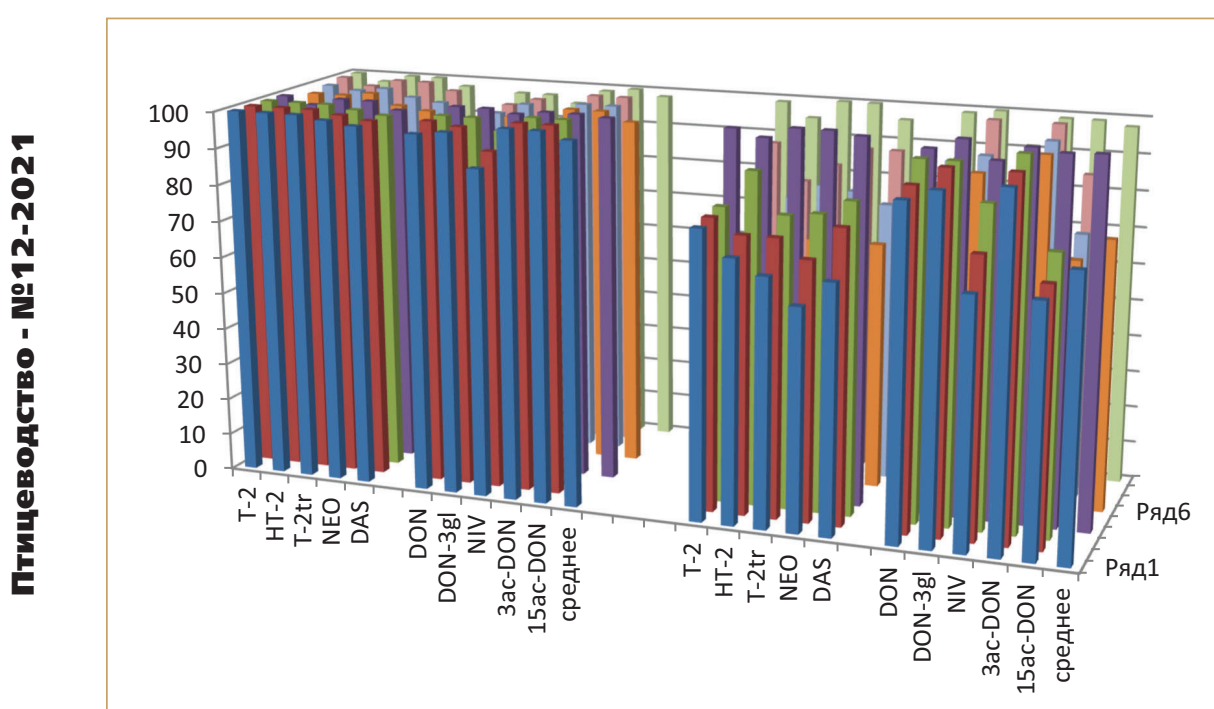

Рисунок 2. Сорбционная ёмкость угля активированного, \%

рабочих растворов проводят в специальных приборах, которые могут поддерживать температуру с шагом $\pm 2{ }^{\circ} \mathrm{C}$ и обеспечивать постоянное встряхивание (рис. 1).

4. Концентрация микотоксинов в рабочем растворе и отношение КД / микотоксин. В некоторых публикациях указывают соотношение токсин:сорбент 1:1000 [9]. Но, как правило, процесс приготовления рабочего раствора микотоксинов описывается без указания данного соотношения. В одном эксперименте применяется метод построения изотермы адсорбции, когда ряд одинаковых навесок сорбента перемешивают с растворами адсорбата с нарастающей концентрацией в течение времени, достаточного для установления адсорбционного равновесия (определяют по кинетической кривой) [2].

Указанные отличия в методиках оценки сорбционной емкости КД могут приводить к различным результатам при исследовании одного и того же вещества раз- ными лабораториями. Необходима разработка единой, легко воспроизводимой методики in vitro, адекватно оценивающей сорбционную способность КД. Также существует необходимость разработки методик такой оценки для разных типов сельскохозяйственных животных. Например, важной особенностью моторики В тонком кишечнике птиц является частая антиперистальтика. Это означает, что химус будет иметь слабощелочную реакцию, и поэтому процессы десорбции могут быть менее интенсивными.

В биохимической лаборатории отдела физиологии и биохимии ФНЦ «ВНИТИП» РАН была унифицирована и отработана внутрилабораторная методика определения in vitro сорбционной емкости разных по составу КД для сельскохозяйственной птицы в отношении трихотеценовых микотоксинов. Методика прошла отработку на более чем 30 препаратах. Способность КД к сорбции трихотеценовых микотоксинов типа А (Т-2 токсин, НТ-2 токсин, Т-2 триол, диацетооксискирпенол, неосоланиол) и В (дезоксиниваленол, нивале- нол, 3-ацетил-дезоксиниваленол, 15 -ацетил-дезоксиниваленол, дезоксиниваленол-3-гликозид) изучали в 4 дозировках КД, с изменением кислотности среды (рН от 1,0 до 7,0), с различной концентрацией микотоксинов в рабочих растворах (соответствующих уровню выше и ниже ПДК в зерне), с изменением времени инкубации растворов (от 30 до 180 мин). Сорбционную способность КД определяли по разности между адсорбцией и десорбцией микотоксинов из растворов. Определение концентрации микотоксинов в рабочих растворах проводилось методом ВЭЖХ-МС/ MC с использованием хроматомасс-спектрометра в комплектации жидкостной хроматограф Agilent Infinity 1260 LC Systems (Германия) и масс-спектрометр AB SCIEX Triple QuadTM 5500 (США).

Для подтверждения работоспособности методики было проведено исследование угля активированного на способность сорбировать трихотеценовые микотоксины. Уголь активированный, как мощный сорбент, показал способность к сорбции трихотеценовых микотоксинов от 60 до 100\% (рис. 2).

Унифицированная методика будет способствовать правильному выбору адсорбента в условиях хозяйств. Но следует не забывать о необходимости располагать оперативными и достоверными сведениями о содержании микотоксинов в кормах. Также необходимо внимательно изучать наставления по применению препаратов: в них приводится более достоверная информация, чем в рекламных проспектах и кратких изложениях наставлений. Очевидно, что для принятия обосно- 
ванного решения придется потратить немало времени, но в этом и состоит работа специалистов [1 1].

\section{Литература}

1. Бурдаева, К. Средства борьбы с микотоксинами. Краткий обзор рынка // Ценовик. - 2016. - №6. - С. 50-52.

2. Николаев, В.Г. Доклиническое изучение энтеросорбентов: химико-фармацевтический аспект / В.Г. Николаев, И.И. Геращенко, Н.Т. Картель, Н.М. Гурина, О.Н. Бакалинская, В.В. Сарнацкая, Е.А. Снежкова, К.И. Бардахивская, Л.А. Сахно // Поверхность. 2011. - №3. - C. 310-319.

3. EFSA, Review of mycotoxin-detoxifying agents used as feed additives: mode of action, efficacy and feed/ food safety EFSA Journal Reference number of the call for proposal: CFP/ EFSA/FEEDAP/2009/01 [Электронный pecypc] URL:http://www.adiveter.com/ ftp_public/A1041209.pdf

4. Крюков, В.С. Эволюция адсорбентов микотоксинов // РацВетИнформ. 2014. - №5. - С. 32-36.

5. Ахмадышин, Р.А. Применение адсорбентов микотоксинов в животноводстве и птицеводстве / Р.А. Ахмадышин, А.В. Канарский, 3.А. Канарская, М.Я. Тремасов, Э.И. Семенов // Ветеринарный врач. - 2006. - №1 . - С. 64-66.

6. Дворская, Ю.Е. Адсорбенты микотоксинов: на что обратить внимание? // Корма и факты. - 2010. - №4. - С. 14-15. 7. Йылдырым, Е.А. Изученик истинной сорбционной емкости сорбента микотоксинов Заслон / Е.А. Йылдырым, Л.А. Ильина // Вестник Бурятской ГСХА им. В.Р. Филиппова. 2018. - №1. - С. 122-126.

8. Зеленченкова, А. Клиноптилолит в кормлении свиней / Зеленченкова
А., Некрасов М., Чабаев М., Гогина Н., Шевяков А., Тулунай ч. // Комбикорма. - 2021 . - №9. - С. 88-90.

9. Ивлева, А.Р. Адсорбция Т-2 микотоксинов гидроалкалоидами / А.Р. Ивлева, 3.А. Канарская //Вестник Международной академии холода. - 2016. №4. - С. 16-18.

10. Малков, М.А. Микотоксины - стратегия устранения их влияния на организм сельскохозяйственных животных и птицы / М.А. Малков, В.В. Богомолов, Т.В. Данькова, К.А. Краснов // Ценовик. - 2012. - №2.

11. Крюков, В.С. Оценивать эффективность адсорбентов нужно реально // Комбикорма. - 2014. - №9. C. 100-103.

\section{Для контакта с автором:}

Гогина Надежда Николаевна

E-mail: n.n.gogina@mail.ru

\title{
The In Vitro Methods of the Assessment of Mycotoxin Absorbing Capacity of Feed Additives (A Review)
}

\author{
Gogina N.N.
Federal Scientific Center "All-Russian Research and Technological Institute of Poultry" of Russian Academy of Sciences

\begin{abstract}
Summary: Mycotoxicoses of productive animal and poultry can result in the significant financial losses to the farms and decrease the quality of the products. At present the most effective solution of this problem involves the supplementation of feeds with the additive capable of the absorption and/or chemical deactivation of the congested toxins during the digestion. The diversity of chemical structure and properties of mycotoxins results in different efficiency of these additives toward different toxins. Therefore, the on-farm choice of optimal additives and their effective doses requires knowledge on the range and real concentrations of the mycotoxins in feeds and on the real ability of the additives to the inactivation of target toxins. The ability of an additive to absorb (or inactivate) different mycotoxins could be assessed in the in vitro or in vivo experiments. In the review presented the in vitro techniques are described and compared.
\end{abstract}

Keywords: feed additives, mycotoxins, absorption (inactivation) of mycotoxins.

\section{ФНТП разбития сельского хозяйства продлена до 2030 года}

Президент Владимир Путин подписал указ о продлении до 2030 года федеральной научно-технической программы (ФНТП) разбития сельского хозяйства. Документ размещен на официальном портале правовой информаиии. Кроме того, срок разработки и реализации мер, напрабленных на создание и бнедрение конкурентоспособных отечественных технологий, основанных на новейших достижениях науки, продлен с 2026-го до 2031 года. 